\title{
Economics and climate applications: exploring the frontier
}

\author{
Debra J. Rubas ${ }^{1, *}$, Harvey S. J. Hill' ${ }^{2}$ James W. Mjelde ${ }^{3}$ \\ ${ }^{1}$ United States Department of Agriculture, Foreign Agricultural Service, 1400 Independence Avenue SW, Stop 1034, \\ Washington, DC 20250, USA \\ ${ }^{2}$ Agriculture and Agri-Food Canada, Prairie Farm Rehabilitation Administration, Room 1101, 11 Innovation Blvd., \\ Saskatoon, Saskatchewan S7N3H5, Canada \\ ${ }^{3}$ Department of Agricultural Economics, Texas A\&M University, College Station, Texas 77843-2124, USA
}

\begin{abstract}
The economics of information is a broad field covering all aspects of information including decision making. We briefly describe 4 methods used to model the decision-making process. This is not an exhaustive list of the methods used to value information, nor are differences between the methods clearly definable. Examples of previous studies using each methodology are presented, as are tradeoffs between the methodologies. Climate forecast issues are generally treated by economists as applied problems. Though applied studies are extremely important, we believe climate forecast issues have the potential for more innovative and rigorous treatment that could lead to theoretical advances in the economics of information. Several examples of researchable issues that we believe could lead to such advances (e.g. the use of climate forecasts in pollution trading; natural disaster mitigation) are then discussed. Maximum benefits can be attained from such a research process that involves policy-makers and end-users, as well as other scientists.
\end{abstract}

KEY WORDS: Economics · Climate applications · Decision theory · General equilibrium modeling · Game theory $\cdot$ Mechanism design theory

\section{INTRODUCTION}

At its core, economics is about making choices. Economic agents are assumed to be rational and to make choices that maximize their expected utility given the information that is available to them. The more accurate the available information, the better the decisionmaker will be able to predict the outcome associated with possible decisions, and thus make better choices. Current and improved climate forecasts can provide information to a wide range of decision makers. Their ability to use information determines its value of the information. In the present study, rather than overlapping with previous reviews of the literature on the use of economic methodology to address climate forecast issues (see e.g. Hill \& Mjelde 2002), we focus first on 4 methodologies used by economists to model decision-making (and thus to determine the value of information). Though other methodologies have provided invaluable contributions to the economics of information and the valuation of climate forecasts, they are not discussed due to space limitations.

In the second part of the paper, examples of current studies are presented along with ideas for future studies. Climate forecast problems provide a wealth of opportunities to advance our applied and theoretical understanding of the economics of information. Although a few studies have attempted to advance theoretical frontiers, the vast majority of climate forecast studies have been applied rather than theoretical. Applied studies often lead to theoretical developments, but we feel economists can do more to use climate forecast issues to advance the theoretical underpinnings of the economics of information. To accomplish this, more innovative and rigorous studies are necessary. This is not to imply all previous studies lack these qualities, but in our opinion, another simple economic study stating that climate forecasts have 
value to society is of marginal benefit. By rigor, we mean logically precise (and not necessarily with an increased mathematical orientation, which many economists equate with rigor).

\section{MODELING APPROACHES}

Four methodologies commonly used to model decision-making are: decision theory, general equilibrium modeling, game theory, and mechanism design theory. The lines of demarcation between these methodologies are fuzzy, at best. Moving from one methodology to the next generally leads to increasing complexity in the interactions between decision makers. Each methodology is appropriate in different situations, depending on the goals of the research and the assumptions about the decision-making process. As one would expect, tradeoffs exist among the methodologies.

\subsection{Decision theory}

Decision theory is an interdisciplinary area of study involving researchers from mathematics, statistics, economics, philosophy, management, and psychology. In its purest form, decision theory involves a single agent, who must make decisions to maximize (minimize) an objective. Other decision makers' choices and institutional factors are assumed fixed. That is, the decision maker makes decisions based solely on the effect of the decisions on his/her payoffs.

In studies of climate applications, the most widely used form of decision theory assumes that preferences among risky alternatives can be described by the maximization of a utility function. Probability theory and climate sciences are used to obtain the probability of climate events. Decision makers are commonly assumed to have prior knowledge that is equal to the climatological or historical probabilities of the distributions of climate variables. Without a climate forecast, the decision maker uses his/her prior knowledge to make the optimal decision(s), but with a forecast, the decision maker uses the forecast to make optimal choices. The value of the forecast is the difference between the payoffs when the forecasts (updated knowledge) are used relative to the payoffs when only prior knowledge is used.

Although many different configurations of decision theory exist, only one mathematical form is presented here. The decision maker's problem is to maximize expected utility by choosing from a decision set using only their prior knowledge. Mathematically, the problem is

$$
u(H)=\max _{D} E_{c}[u(D, c) h(c)]
$$

where max is the maximization operator, $u(H)$ is the maximum expected utility using climatological information; $\mathrm{E}_{\mathrm{C}}$ represents the expectation operator for the range of climate conditions of interest, $\mathrm{c}$; h(c) represents the historical probability density function of climate conditions; $u$ represents the utility function; and D represents the decision set. Embedded within this equation are all the aspects that affect the decision process, such as institutional rules and risk aversion. When climate forecast $\left(\mathrm{F}_{\mathrm{i}}\right)$ becomes available, the probability density function of climate conditions is represented by $\mathrm{g}\left(\mathrm{ClF}_{\mathrm{i}}\right)$. The decision-maker's problem is

$$
u_{i}\left(F_{i}\right)=\max _{D} E_{\left(c \mid F_{i}\right)}\left[u(D, c) g\left(c \mid F_{i}\right)\right]
$$

where i represents the forecast and $\mathrm{E}$ is the expectation operator. Forecast $F_{i}$ is only one of many possible forecasts. Expected utility associated with the entire forecasting system, $F$, is

$$
\mathrm{u}(\mathrm{F})=\mathrm{E}\left[\mathrm{u}_{\mathrm{i}}\left(\mathrm{F}_{\mathrm{i}}\right) \mathrm{Z}\left(\mathrm{F}_{\mathrm{i}}\right)\right]
$$

where $\mathrm{Z}\left(\mathrm{F}_{\mathrm{i}}\right)$ is the probability density function associated with the probability of receiving each forecast. The value of the forecast system is

$$
\mathrm{V}=\mathrm{u}(\mathrm{F})-\mathrm{u}(\mathrm{H})
$$

where $\mathrm{V}$ represents the difference between the expected utility with the use of seasonal forecasts versus expected utility using only prior knowledge. If $\mathrm{V}$ is in utility terms, the difference in utility can be placed in monetary units by using certainty equivalence dollars (Mjelde et al. 1996). When risk neutrality is assumed, V is in monetary units. Over all possible climate forecasts, the probability of climate events must equal the climatological probabilities. With the above equations, decision theory determines the value of using climate forecasts.

The majority of seasonal climate forecast studies have used decision theory (e.g. Ritchie et al. 2004, Maurer \& Lettenmaier 2004, Everingham et al. 2003). This is largely because decision theory is the least complicated of the 4 approaches in terms of the number of decision makers considered. A researcher has only to account for the decision process of 1 economic agent. Even so, the process is complicated. Decision theory is appropriate when the choice of 1 decision maker can neither affect the outcome for another decision maker nor the rules of the process. For example, a single agricultural decision maker interested in adopting climate forecasts would have little impact on supply or demand and would therefore have little impact on price.

Following are several additional examples of studies that use decision theory to estimate the value of climate forecasts. Meza \& Wilks (2004) estimate that perfect forecasts of sea surface temperature anomalies have a value of US\$5 to $\$ 22$ per hectare for potato 
fertilization management. Imperfect forecasts have approximately $60 \%$ of the value of perfect forecasts when the initial fertilization level was not optimal. Jones et al. (2000) compare the value of El Niño Southern Oscillation (ENSO)-based climate forecasts in Tifton, Georgia, USA with values for the Pampas region of Argentina. Similar crops are considered, but because they are in different hemispheres, they are grown at different times during the year. For maize management, expected values of the forecasts were US\$13 for Tifton and \$15 for Pergamino, Argentina. The authors state that the estimated economic potential is very high considering the large areas of field crop production in these regions (Jones et al. 2000). Hamlet et al. (2002) estimate that use of climate forecasts in the management of hydroelectric dams on the Columbia River can increase energy production by 5.5 million $\mathrm{MW} \mathrm{h}{ }^{-1} \mathrm{yr}^{-1}$, resulting in a US\$153 million increase in net revenues. They explicitly assume the monthly prices are '... unaffected by the relatively small shifts in energy production from spring to fall examined here' (Hamlet et al. 2002, p. 98). While assuming away price effects may be appropriate when considering a single economic agent, it is inappropriate when considering a large number of producers or a large impact on the supply and demand conditions of the process. In these cases, other methodologies must be used.

\subsection{General equilibrium modeling}

General equilibrium modeling deals with trade and production. This approach explicitly recognizes that the choices of different decision makers are interlinked. If one producer uses climate forecasts, prices will not change because the production of a single producer is very small relative to total (aggregate) production. But as the number of producers using climate forecasts increases, the change in aggregate production will cause price changes. Producers who do not anticipate this change may not make optimal choices.

Leon Walras, who first presented his equations of equilibrium modeling in 1874, is considered the founder of general equilibrium theory (Hansen 1982). The following simplified demand and supply system illustrates the concept of general equilibrium modeling. Assume there are $n$ goods in the economy, in which the price of each good is expressed relative to good $n$. By expressing the price relative to a good, the price is being '... defined as an exchange relationship between 2 goods, one of which is chosen as a standard of value, a numéraire' (Hansen 1982, p. 25-56). With $n$ goods we have $n-1$ prices, $\pi_{1}$ to $\pi_{n-1}$. The price of the numéraire good, $n$, is 1 ; the price relative to itself is 1 .
General equilibrium modeling is concerned with supply and demand relationships. The $n$ demand relationships are

$$
\mathrm{q}_{\mathrm{i}}^{\mathrm{d}}=\mathrm{q}_{\mathrm{i}}^{\mathrm{d}}\left(\pi_{1}, \pi_{2}, \ldots, \pi_{n-1}\right) \mathrm{i}=1, \ldots, n
$$

where $q_{i}^{d}$ is quantity of the good i demanded. Similarly, there are $n$ supply relationships

$$
\mathrm{q}_{\mathrm{i}}^{\mathrm{s}}=\mathrm{q}_{\mathrm{i}}^{\mathrm{s}}\left(\pi_{1}, \pi_{2}, \ldots, \pi_{n-1}\right) \mathrm{i}=1, \ldots, n
$$

where $\mathrm{q}_{\mathrm{i}}^{\mathrm{s}}$ is quantity of the good i supplied. The equilibrium conditions are

$$
\mathrm{q}_{\mathrm{i}}^{\mathrm{d}}=\mathrm{q}_{\mathrm{i}}^{\mathrm{s}} \mathrm{i}=1, \ldots, n
$$

Notice that changes in the supply or demand of one good are linked to changes in the other $n-1$ goods. The use of climate forecasts has been shown to affect the on-farm production of commodities. It is these changes that impact the supply of the commodity, thus affecting the equilibrium of other goods through the above relationships.

General equilibrium modeling has not been used in applications of seasonal climate forecasts. The obvious reason is the enormous complexity. As Hansen (1982, p. 33) states, 'Increasing generality must be paid for by increasing abstraction and decreasing concreteness.' In other words, there are trade-offs. At one extreme, a researcher can model an individual's decision-making process in detail and ignore supply and demand relationships, which can lead to estimates that over or understate the true value of using climate forecasts. At another extreme, a researcher can get bogged down in trying to include everything. At a third extreme, the model can become too general to be of real use.

Studies have used general equilibrium concepts to develop partial equilibrium models, sector models, and trade models of particular crops to examine the effects of climate forecast use. Crop-growth simulation models have generally been used in conjunction with decision theory models to obtain producers' production responses from forecast use. The models then develop aggregate supply relationships. Changes in aggregate supply caused by the use of climate forecasts affect price, which is endogenous to these models. Individual producers take aggregate price changes into account when making decisions.

A series of related studies examines the effect of ENSO-based climate forecasts on the agriculture sector using a previously developed model of the US agriculture production sector (Chen \& McCarl 2000, Chen et al. 2001, 2002). Chen \& McCarl (2000) and Chen et al. (2001) report that producer surplus decreases by using ENSO-based forecasts, but consumer surplus increases enough that overall social welfare increases. Inclusion of rest-of-the-world ENSO effects had little 
impact on the overall value of ENSO-based forecasts but did redistribute some gains. In their model, foreign surplus gains are minor compared to US surplus gains. Chen et al. (2002) report that using the 5-phase ENSO definition of Stone \& Auliciems (1992) almost doubles social welfare gains compared to the more standard 3-phase definition. Using a similar conceptual model as the previous studies, Adams et al. (2003) report the value of an ENSO-based system to be US\$10 million annually for Mexican agriculture. Mjelde et al. (2000) use a previously developed dynamic model to show that use of seasonal forecasts in the production agricultural sector will affect machinery manufacturers, food processors and retailers, and the financial sector.

Hill et al. (2004) combined supply and demand relationships (estimated using historical data) with estimated production changes caused by climate forecast use. While other studies used previously developed models, Hill et al. (2004) developed a dynamic international wheat trade model specifically for examining climate forecast issues. Previous studies found that when producers use climate forecasts, prices decrease because of an increase in production. These price and production changes cause producers to lose and consumers to gain. Such a result is commonly associated with agricultural commodities and production advances. Demand of agricultural commodities tend to be price-inelastic. For commodities with price-inelastic demands, the percentage increase in quantity produced is less than the percentage decrease in price, resulting in a decrease in total revenue to producers (Tomek \& Robinson 2003). Hill et al. (2004), however, found that producers worldwide can obtain a large share of the increase in social welfare. Producers are able to adjust their inputs so that they are used more efficiently, thus increasing their welfare despite a price decrease. An overview of this model is presented in Fig. 1 to illustrate the complexity of equilibrium modeling. Each country has its own supply and demand relationships, and there are price and trade linkages between countries. As more crops or sectors are added, the complexity and costs of modeling increase.

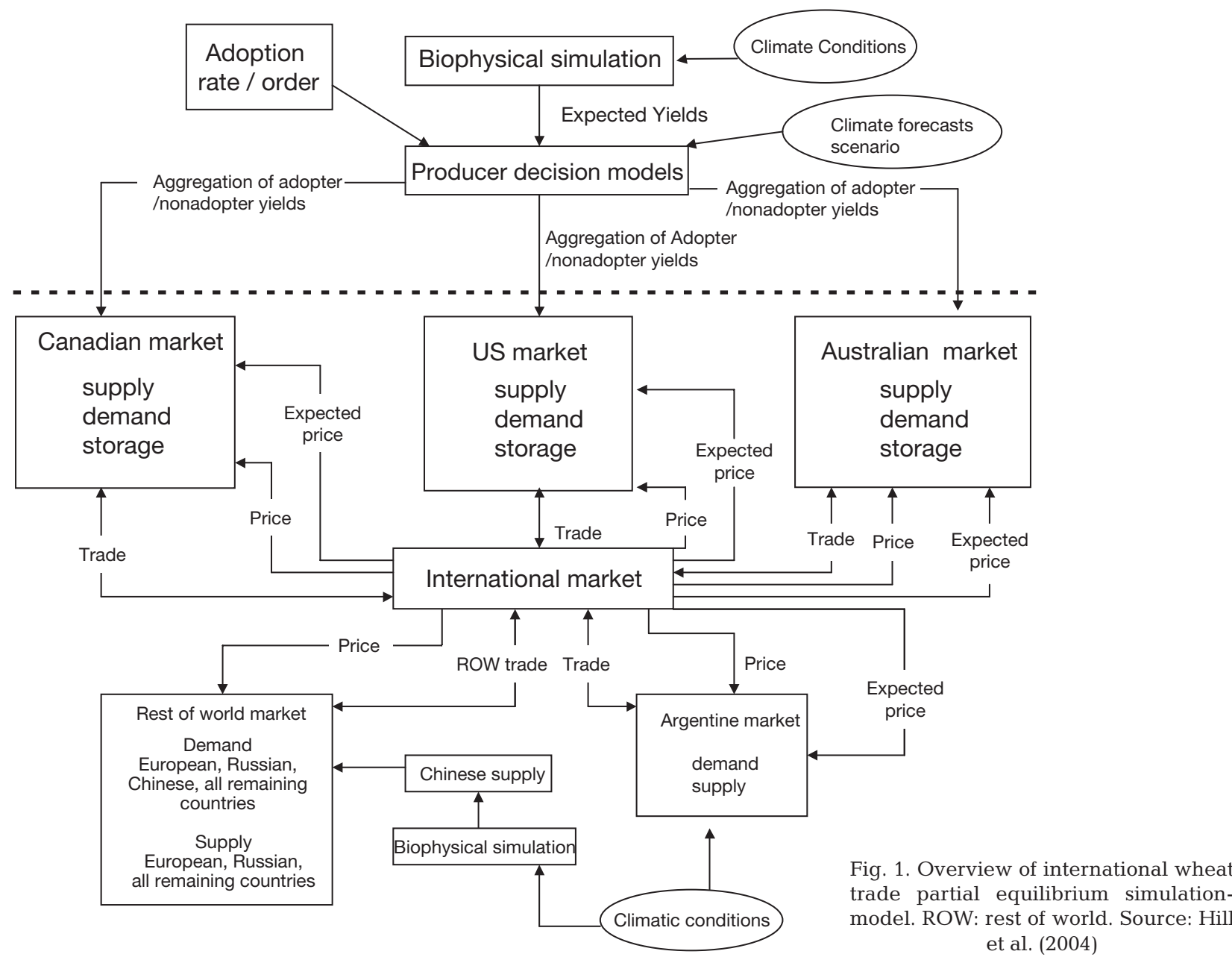




\subsection{Game theory}

Like decision theory, game theory is of interest to many disciplines. The roots of game theory have been traced as far back as 0-500 AD (Walker 2005, available at: www.econ.canterbury.ac.nz/personal_pages/paul_ walker/gt/hist.htm). Although by no means new, the methodological aspects of game theory are rapidly evolving and have become commonplace in mainstream economics. As noted, the distinctions between decision theory, equilibrium modeling, and game theory are fuzzy. In decision theory, the decision maker's choice has no effect on anybody but him/herself. This is not the case in game theory. 'Game theory is concerned with the actions of individuals who are conscious that their actions affect each other' (Rasmusen 1992, p. 21). The concepts of game theory can easily be shown by the classic 2-player Prisoner's Dilemma problem shown in Table 1 (Rasmusen 1992). Prisoner B does not know what Prisoner A will do when Prisoner $\mathrm{B}$ is making a decision. The same holds true for Prisoner A. Consider Prisoner B's options. If Prisoner A chooses 'cooperate,' Prisoner B will spend $1 \mathrm{yr}$ in prison if he chooses 'cooperate' and no time in prison if he chooses 'do not cooperate.' If Prisoner A chooses 'do not cooperate,' Prisoner B gets $10 \mathrm{yr}$ in prison if he 'cooperates' and $8 \mathrm{yr}$ if he chooses 'do not cooperate.' For either of Prisoner A's choices, Prisoner B does better by choosing 'do not cooperate.' Since the game is symmetrical, Prisoner A's outcomes are the same as B's. Both players choose 'do not cooperate,' and each spends 8 yr in prison. The 2 players would have been better off if they had cooperated. Each would have spent only 1 yr in prison. Rasmusen (1992) shows that

Table 1. Classic prisoner dilemma game, where the payoffs are years in prison for Prisoner B, Prisoner A. Adopted from Rasmussen (1992)

\begin{tabular}{|lcc|}
\hline \multirow{2}{*}{ Prisoner B } & \multicolumn{2}{c|}{ Prisoner A } \\
& Cooperate & Do not c ooperate \\
\hline Cooperate & 1,1 & 10,0 \\
Do not cooperate & 0,10 & 8,8 \\
\hline
\end{tabular}

the information structure of the game does not matter. For example, even if Prisoner A knows Prisoner B's move before making a choice, the outcome will not change. Prisoner B knows that A's best move is 'do not cooperate,' regardless of what B does. B's dominant strategy is thus 'do not cooperate.' Rasmusen (1992, p. 29) states, 'Whenever you observe individuals in a conflict that hurts all of them, your first thought should be of the Prisoner's Dilemma.' The Prisoner's Dilemma arises in many situations, including political bargaining, auction bidding, and arms races. By no means is the Prisoner's Dilemma the only game, but it serves as a simple example to illustrate the strategic nature of players within a game. Payoffs in game theory are often obtained through decision theory and/or equilibrium modeling, interlinking the various methodologies.

Game theory has not been widely used in applications of seasonal climate forecasts largely because of the increase in information requirements and increased methodological knowledge necessary to develop and solve games. One recent application is Rubas et al. (2005). Using an updated version of Hill et al.'s (2004) international wheat trade model (see Fig. 1), Rubas et al. (2005) develop a 3-player game. To develop the model and game, decision theory was used at the field level then aggregated to develop a partial equilibrium model. This model provides the payoffs for the players in the game. The 3 players are the USA, Canada, and Australia. Producers in each country can either use climate forecasts or not use them. The payoffs are increases in expected producer surplus (Table 2). Payoffs vary based on which country(ies) use climate forecasts. Because of economic linkages, adoption by one country affects the other countries. The dominant strategy for each country is to use ENSO-based climate forecasts. Consider, for example, Canada's payoff in Table 2. If only Australia adopts the use of climate forecasts, Canada's producers lose, whereas if either Canada or the USA adopts, Canadian producers gain. Canadian producers gain the most if both the USA and Canada adopt, and Australia does not adopt. Results are similar for the USA and Australia. Regardless of the other countries' decisions, each country's highest payoff oc-

Table 2. Mean percentage changes in present value producer surplus over $20 \mathrm{yr}$ for 1000 simulations assuming no adoption or $100 \%$ adoption of ENSO-based climate forecasts by wheat producers in Australia, the USA, and Canada. Source: Rubas et al. (2005)

\begin{tabular}{|lrrrrccc|}
\hline & & & \multicolumn{5}{c|}{ Countries that adopt climate forecasts } \\
& Australia & Canada & USA & Canada, Australia & USA, Australia & USA, Canada & USA, Canada, Australia \\
\hline Australia & 6.29 & 0.06 & 1.01 & 6.56 & 7.19 & 1.13 & 7.53 \\
Canada & -0.15 & 0.59 & 1.32 & 0.52 & 1.20 & 1.37 & 1.33 \\
USA & 0.06 & -0.28 & 2.83 & -0.34 & 2.76 & 2.29 & 2.22 \\
\hline
\end{tabular}


curs when it chooses to use climate forecasts. The USA gains the most when it alone adopts climate forecasts, whereas Australia gains the most when all 3 countries adopt. Canadian and USA losses associated with Australia adopting are not as large as gains from adopting. Results suggest that cooperation between countries can increase the gains worldwide from climate forecast use.

Both the Prisoner's Dilemma and Rubas et al. (2005) are examples of non-cooperative games. In noncooperative game theory, players do not discuss their choices. Each acts individually. In cooperative games, on the other hand, players agree how they will choose prior to making their choices. As shown in the prisoner's dilemma and Rubas et al. (2005), players acting alone often do not gain as much as they would if they acted together. To the authors' knowledge, cooperative game theory has not been applied to climate forecast applications. Climate applications are a perfect area to explore cooperative game theory and an exciting opportunity for this traditionally applied subject to push the frontiers of economic theory.

Though rarely used in studies on climate forecast problems, game theory has been used in climate related studies such as climate change studies (Ward 1996, Forgo et al. 2005) and climate variability studies (McKelvey et al. 2003). McKelvey et al. (2003) conclude that better science alone will not lead to more efficient management of our international fisheries. There is a need for flexible cooperative arrangements between nations based on fish populations. This result leads into the next methodological approach.

\subsection{Mechanism design theory}

Decision theory, general equilibrium modeling, and game theory all assume the rules of the process are fixed. In mechanism design, the rules players operate under become part of the process. The consequences of different rules along with strategic behavior of the players become important. In mechanism design, one player, denoted the principal, conditions his/her actions on the information that is known by the other players, called agents. As noted by Fudenberg \& Tirole (1991), what distinguishes this approach is that the principal is assumed to choose the mechanism that maximizes his/her expected utility, rather than making a choice based on historical or institutional reasons. Fudenberg \& Tirole (1991) use auctions as a way of distinguishing game theory from mechanism design theory. Game theory models would solve for each buyer's optimal bidding strategy using different auction mechanisms, such as first-price and second-price auctions. Mechanism design asks which form of auction (first- or second-price) maximizes the principal's (seller's) expected revenue. The auction form becomes endogenous to the decision-making process. Under different situations, either type of auction can be optimal. Mechanism design theory becomes very mathematical in nature and is, therefore, not described in further detail here. There are many areas in which mechanism design and game theory could be applied to climate forecast issues. Two such areas are insurance and futures markets.

To our knowledge, only one exploratory study has applied mechanism design theory to seasonal climate forecast issues. Sheriff \& Osgood (2005) investigate the role of game theory mechanisms in developing and applying livestock health monitoring and forecasting systems. They conclude the best contract design requires the buyer to compensate the producer for revealing private information on livestock health. The goal of such studies is to find the best possible set of market/institutional rules so the use and associated value of climate forecasts benefit individuals or society the most. Using mechanism design to determine optimal institutional arrangements is one way to increase the value of using climate forecasts. This statement is based, in part, on a study by Glantz (1977, p. 156-157), who concluded:

'This preliminary assessment leads to the tentative conclusion that, given the national structures in the Sahelian States in which a potential technological capability would be used, the value of a long-range forecast, even a perfect one, would be limited. It appears, however, that its value could be greatly enhanced if its implementation were to be coupled with the removal of the numerous social, political, and economic obstacles ...'

Changing the rules (institutions) to increase the value of climate forecasts is relevant not only to developing countries. Scott et al. (2004) conclude that simple changes in institutions would allow climate forecasts to be used to reduce water shortages in western states of the USA during El Niño episodes.

\subsection{Concluding comments on methodology}

All 4 methodological approaches are important in certain situations, though decision theory has been used most frequently in climate forecast applications. In many cases, decision theory has been the most appropriate methodology because the research focused on the choices of a single agent. As we move beyond a single agent, however, to look at more realistic scenarios where multiple producers use climate forecasts, advances in the other 3 methodologies become extremely important. It is obvious that climate forecast studies benefit from methodological advances, but what about 
the other way around: Can climate forecast applications help to advance the methodologies? We think the answer is a resounding yes!

\section{FUTURE OF CLIMATE FORECAST MODELLING ECONOMICS}

In this section, we present examples of current or potential studies that we feel illustrate innovation and rigor. We feel current understanding of climate forecast issues has reached the point of declining marginal net benefits for applied studies of a single decision maker for a single field assessing the value of climate forecasts based on input usage. The economics in many previous studies consists only of price times yield minus costs. To advance scientific knowledge and engage economists, more academically challenging problems must be addressed. We therefore suggest several researchable issues that would not only advance our knowledge of the impact of climate forecast use, but also increase our theoretical and general understanding of the economics of information. Some of the issues are already receiving a limited degree of attention. Climate forecast problems provide a unique opportunity to make advances in theoretical knowledge - in addition to the existing applied knowledge — on the economics of information.

\subsection{Publishing trends}

Using the ISI Web of Knowledge search engine (available at http://isi9.isiknowledge.com/portal.cgi/), we searched for 'climate and forecasts' and then 'climate and forecasts and value'. Databases searched were: Science Citation Index Expanded, Social Science Citation Index, and Arts \& Humanities Citation Index. Though the ISI Web of Knowledge is limited in that it does not cover all published scientific sources and its sources have changed over time, it still provides a convenient low-cost source to judge interest. The search using 'value' is used to show applications of climate forecasts. While no single search term is perfect, the general trend was similar using different search terms.

The total number of articles for the 2 searches by year is given in Fig. 2. There is an upward trend in the total number of articles starting about the time the scientific community recognized the potential relation- ship between the ENSO and worldwide climate conditions. As expected, increases in articles associated with 'value' lag behind the total number of articles. Most applications of climate forecasts occurred only after the realization that improved climate forecasts were possible. We hope that the increasing trend will continue.

The percentages of articles by the journals' primary subject matter for the years 2000-2004 are given in Fig. 3 for the 'climate and forecast and value' search. The majority of publications are in climate subject matter journals. A smaller number are published in agricultural/forestry and water-oriented journals. It is not surprising that climate forecasts are being applied to agricultural and water issues because of the obvious impact of climate conditions on these areas. Similar results are obtained for the 'climate and forecasts' search.

This anecdotal evidence supports our suspicion that studies of decision making that use climate forecasts have generally been treated by the social sciences as an applied issue and not an issue that can be used to advance theory. Theoretical developments would tend to be published in discipline-oriented journals. There are several reasons climate issues have been treated as applied issues. (1) There is a lag between the time an advance is made in one discipline and when it is used in other disciplines. Only in the last few years has there been a general acceptance that climate forecasts are improving. (2) Much of the funding for climate research originates from sources that have emphasized stakeholder participation, which generally leads to more applied problem 


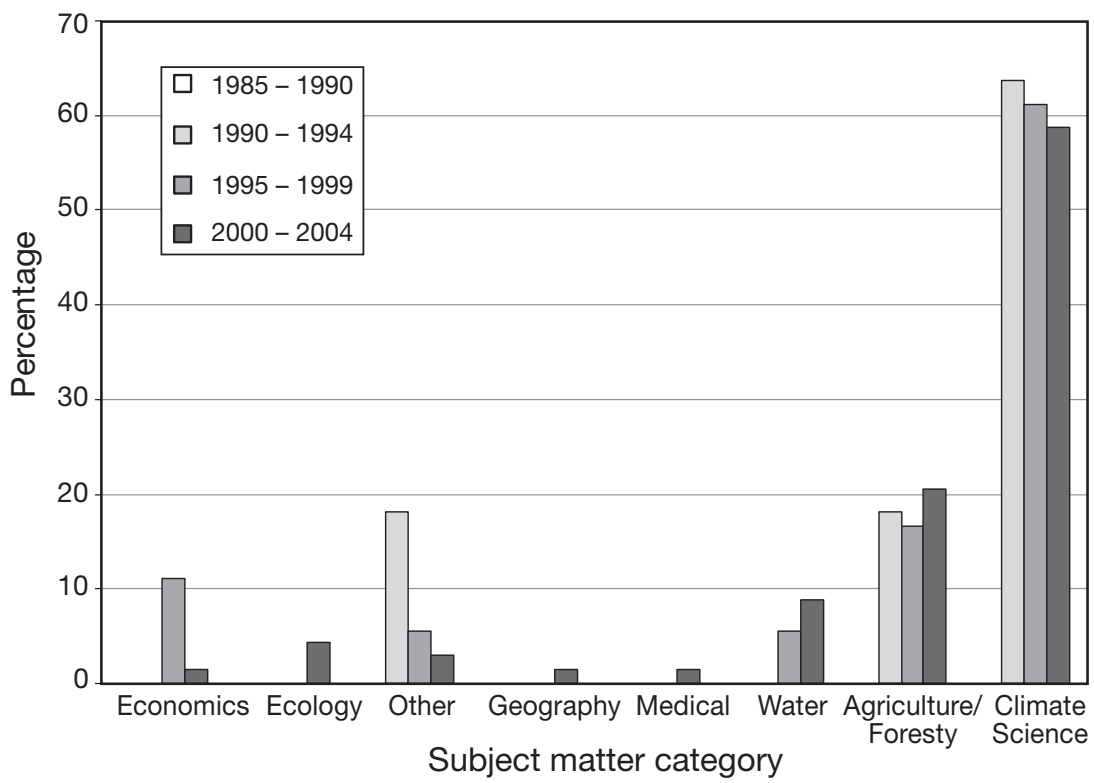

Fig. 3. Percentage of articles reported by 5 yr periods by journal subject matter using ISI Web of Knowledge Search Engine for search of 'climate and forecasts and value'

solving. (3) A lack of communication between disciplines has slowed progress. Statements such as, 'We need only simple economics' and, 'Today's weather can't be forecasted; how can climate be forecasted?' have led to misunderstandings between disciplines and a lack of cooperation. Even with these and other problems, disciplinary and multidisciplinary issues are being addressed and advanced. We believe that climate forecast applications provide a unique setting for disciplinary and interdisciplinary advances in the economics of information.

\subsection{Resource/environmental economics and climate forecasts}

Environmental regulations are changing in light of new discoveries by the physical and social sciences. The natural resources, weather and climate, affect numerous environmental issues. Improved climate forecasts provide new opportunities to help manage our natural resources. Promoting climate forecast research from such a standpoint could help place this research closer to the mainstream of resource economics. For example, most economists feel water marketing is the future for more efficient water management. As noted earlier, it may be necessary to change institutions to take better advantage of advances in water management and climate sciences. One could envision a water marketing setup that is based on forecasted precipitation levels. We expand on a similar idea in the next section for pollution trading.

\subsubsection{Pollution trading}

Advances in climatology and other sciences can be combined to provide valuable information to help policy makers improve institutional arrangements. One idea is to combine advances in efficient pollution control mechanisms (pollution trading) with increases in our ability to forecast climate conditions. To our knowledge, combining these 2 advances has not yet been attempted. Potential environmental impacts associated with changes in input usage stemming from the use of climate forecasts have been noted but are generally ignored. Hill et al. (1998) note one such impact; the expected aggregate amount of applied nitrogen on sorghum in Texas will decrease with the use of ENSO-based climate forecasts. Water quality is sensitive to climate variability because of the effect precipitation has on the ability of the environment to assimilate and dilute pollution. Because of the sensitivity of water quality to climate conditions and changes in input usage caused by climate forecast use, information about climate variability might be exploited by policy makers to improve the efficiency and effectiveness of pollution control mechanisms.

One such mechanism may be market-based policies such as pollution-trading schemes. This relatively new mechanism could be designed such that rules are based on forecasted climate conditions. For example, years with a high forecasted rainfall, and thus, runoff may have a different set of trading rules than years with low forecasted rainfall. Developing flexible pollution-trading rules based on climate forecasts may lower the costs associated with reaching environmental quality goals. However, flexible rules would also affect firms' risk and profitability. It is not clear if such institutional changes would be synergistic or competitive in terms of water quality and the firms' profitability. If studied together, one could determine how climate forecasts and environmental polices can be used jointly to improve watershed management.

\subsubsection{Natural disaster mitigation}

There is also a recognized need to link climate information to development issues and hazard mitigation. At the January 2005 United Nations world conference on natural disaster reduction held in Kobe, Japan, climate extremes were identified as the major source of disaster risk in the world: 
'Disaster risk arises when hazards interact with physical, social, economic, and environmental vulnerabilities. Events of hydrometeorological origin constitute the large majority of disasters. Despite the growing understanding of and acceptance of the importance of disaster risk reduction and increased disaster response capacities, disasters and in particular the management and reduction of risk continue to pose a global challenge' (UN 2005, p. 3).

Thalwitz (1990) states that development enables exante precautionary measures to be implemented that allow for enhanced resilience in developing countries. Climate information and forecasts combined with information and research from other physical and social sciences have the potential to achieve the development of the ex ante precautionary measures Thalwitz (1990) advocates. Progress has been slow as the complexity of the research and application associated with linking climate information to physical and economic models has proven to be challenging. This is an area, however, that holds promise to both the public and private sectors, as nations and financial institutions such as the World Bank and insurance corporations attempt to identify combinations of resiliency strategies that enhance development and reduce risk. Motivators for this include recent events in developed and developing countries such as the devastation caused by Hurricane Mitch in Honduras in 1997, the floods in Mozambique in 2001 and Europe in 2002, the recent tsunami that devastated parts of Southeast Asia, and the major hurricanes that impacted the USA in 2004 and 2005.

\subsubsection{Climate change}

Climate change adds an additional layer of complexity to economic analysis. Because of the magnitude of the problem, most economic analyses have focused on global climate models. The questions they have tried to address include the cost of sequestering carbon and impacts on various sectors associated with climate change. This analysis is hampered by the limitations of current climate models. Temperature trends tend to be in agreement across all models. However, precipitation is less homogeneously modeled. Policy makers face a number of challenges in assessing the economic impact of climate change. The response has been to produce complex integrated models linking climate models to biophysical and economic models. These models provide a sense of the relative changes in economic activity forecasted for differing levels of greenhouse gases and differing policy initiatives. There is increasing recognition that economic analysis of climate change must occur at a finer spatial scale. There are also questions as to how much economic impact can be attributed to cli- mate change, as the link between the cost of natural disasters and climate change has yet to be completely established (Changnon et al. 2000, Sarewitz \& Pielke 2005, available at: http://sciencepolicy. colorado.edu/ admin/publication_files/resource-1694-2005.01.pdf). Also, the economic implications of adaptation strategies to current climate change need to be more carefully addressed. Finally, economic analysis is hampered by the lack of knowledge regarding the variance around the predicted climate trends. Despite these constraints, progress is being made in identifying characteristics of markets resilient to climate variability and the creation of economically viable greenhouse gas trading mechanisms. Research addressing climate forecasts as another adaptation strategy for climate change holds promising rewards, even given the above issues. Combining innovative marketing institutions with improved climate information much along the lines set by the pollution-trading example would allow market incentives to play an important role in dealing with potential consequences associated with climate change.

\subsection{Climate forecast use}

\subsubsection{Adoption of climate forecasts}

The climate-forecast literature tends to ignore the dynamic aspects of climate-forecast use. Adoption of climate forecasts by decision makers takes place over time, and some producers may never adopt. The main reason for ignoring this dynamic aspect is that improved climate forecasts are relatively new, making information on the adoption path scarce. Research can, however, draw on other literature. The obvious candidate is the technology adoption literature. Agrawala \& Broad (2002) argue, 'Seasonal forecasts, while not a piece of hardware, are certainly a knowledge product, and therefore they do fall within the purview of 'technology'.' In addition, climate forecasts share characteristics with technological advances, which are generally adopted over time. Given the recency of improved climate forecasts, adoption can be examined ex ante. Combining research on technology adoption, climate forecasts, and the economics of information allows the researcher to combine cutting-edge theories and methodologies from different disciplines. Such research would build on the important survey studies on the use of climate forecasts by decision makers.

As noted in many theoretical and applied studies of technology adoption, the rate of adoption has an S-shape over time (see Rogers \& Stanfield 1968). Initially, only a few decision makers use the new technology. The rate of adoption is very low. As word of the technology spreads and others see the benefits, 
more decision makers begin using the technology, and the rate of adoption increases. At some point, all those who believe they can benefit from adoption have adopted, and the rate of adoption goes back to zero. One hundred percent adoption of any technology is extremely rare.

Rubas (2004) examines the adoption of the use of climate forecasts using an S-shaped path, and found that when farmers begin using climate forecasts in their planting decisions, the earliest adopters gain the most and not everybody will use climate forecasts. Adoption ceases when the benefits of adoption equal the benefits of non-adoption. As can be seen in Fig. 4, per hectare producer surplus associated with adopters and non-adopters are equal at an adoption level below $100 \%$. Everybody (adopters and non-adopters) is better off than if nobody had adopted or if everybody had adopted.

Knowing that not everybody will or should adopt climate forecast information does not help policy makers target potential decision makers. Much of the previous research has been directed toward current decision makers. This research has immediate payoffs (in terms of the potential use of climate forecasts), but, given the age of current decision makers, may have a limited longer-term payoff. One innovative idea for longerterm payoffs is to target school age children.

\subsubsection{Educational application}

Education appears to be a key component in the adoption of technology. Nelson \& Phelps (1996, p. 69) state, 'Education enhances one's ability to receive, decode, and understand information.' They go on to hypothesize, 'Educated people make good innovators, so that education speeds the process of technological diffusion' (Nelson \& Phelps 1996, p. 70). Studies specific to the adoption of climate forecasts in the decision-making process have also emphasized decision maker education as a key to the use of climate forecasts (Hill \& Mjelde 2002). One study developed materials to teach decision making and the use of probabilistic information in general, and weather and climate forecasts in particular, to junior high school students (Hoyle et al. 2006). The payoffs will occur in the future, but the payoffs will potentially continue longer as students apply the knowledge in appropriate settings throughout their lives. Key to this study is the idea of teaching students economic concepts including decision theory early in their academic careers (starting in 6th grade). If computer technology is any indication, children have a large influence on the development and use of technologies.

\subsubsection{Integrated research}

Climate information in isolation has relatively little value beyond basic science unless it is integrated into managerial and policy processes. This requires an integrated research program that robustly interacts with decision makers and identifies the needs and environment in which they function. Economics is a necessary component of this research as it provides a gauge of the value of alternative options identified by the research. In integrated research environments, however, a great deal of work is required by all scientists to understand
Fig. 4. Producer surplus over time for (a) US, (b) Canadian, and (c) Australian producers, when the USA starts adopting first, Canada starts adoption second, and Australia starts adoption third. Source: Rubas (2004) 
the role the different disciplines play in the resource allocation and valuation process. Two examples of this type of integrated research are: (1) the Regional Integrated Sciences and Assessment (RISA) program, a NOAA funded program that supports research that addresses complex climate-sensitive issues of concern to decision makers and policy planners at a regional level, and (2) the Agricultural Production Systems Research Unit (APSRU) and the Commonwealth Scientific and Industrial Research Organisation (CSIRO) partnership funded by the Queensland Department of Primary Industries and the Australian Federal Government. These research teams have had success in linking climate information to decision-making in the water, forestry, and agricultural sectors. They have 3 components to their research process: (1) assessments and problem identification, (2) integrated research on tractable research of concern to end users, and (3) provision of information, methodologies, and tools that can help expand decision makers' options. The groups are not consultants; they are scientists who strive to produce the 'next generation' of integrated knowledge methodologies in a manner that is useful to end users. This type of applied research can be a fertile environment for economic analysis. It does require that the economist be willing to invest a significant amount of time in understanding the scientific issues that drive the availability of resources and affect demand. J. D. Sachs states this clearly in an interview he gave on development and economics, 'It isn't possible to do good economic development thinking without understanding the physical environment, deeply, in which economic development is supposed to take place' (Appell 2003, p. 37). The same holds true in the developed world.

\section{CONCLUDING COMMENTS}

Numerous lessons have been learned by incorporating climate information into economic research. (1) Economic analysis has contributed to our understanding of how to incorporate uncertain information into decision-making processes. (2) Economics has proven to be a good bridge between physical and social sciences and between the sciences and decision makers by translating climate-sensitive biophysical information into viable resource allocation choices for producers, consumers, and public institutions. (3) Economics has revealed the conditions under which climate information and forecasts can have value. These studies have demonstrated that investments in climate science have a positive payoff to society. In addition, improved access to data, for example via the Global Earth Observing System of Systems (GEOSS), is likely to provide an increase in opportunities for linking different forms of climate variability to decision making, such as in the production, trade, and processing of climate-sensitive natural resources; water management; disaster management; and infrastructure planning.

There is a broad range of possibilities for future economic research related to climate science. The next generation of work will have the advantage of enhanced biophysical data, in part from the development of the GEOSS and similar projects, which should, in turn, result in improved dynamic weather and climate models. There are also increasingly sophisticated geoinformatics tools available, as well as an increasing confidence in economics as an important aspect of integrated research. Potential research areas will also be broad, spanning the entire temporal and spatial spectrum from sub-seasonal cropping decisions to longterm management of resources and urban environments over the next $100 \mathrm{yr}$.

Finally, several studies (see Hill \& Mjelde 2002) have used the climate forecast context to address more basic issues regarding the economics of information. While these studies have increased the general understanding of the economics of information, we strongly feel that more such studies are necessary. As noted, the 4 methodologies are of interest to a variety of disciplines. Studies addressing methodological approaches and general economics of information would also be valuable to these disciplines. Rigorous disciplinary and interdisciplinary studies hold great promise in advancing theoretical and applied aspects of the economics of information.

Acknowledgements. The views expressed in this paper are the views of the authors and do not necessarily represent the views of the USDA, Foreign Agricultural Service of the United States, Agri-Food Canada / Agriculture et Agroalimentaire, or Texas A\&M University.

\section{LITERATURE CITED}

Adams RM, Houston LL, McCarl BA, Tiscareno ML, Matus JG, Weiher RF (2003) The benefits to Mexican agriculture of an El Niño-southern oscillation (ENSO) early warming system. Agric For Meteorol 115:185-196

Agrawala S, Broad K (2002) Technology transfer perspectives on climate forecast applications: research in science and technology transfer. De Laet M (ed) Knowledge and society, Series 13. Elsevier and JAI Press, Oxford, p 45-69

Appell D (2003) Science to save the world: economist Jeffrey Sachs. Sci Am January 2003 p 36-37. Available at: www.sciam.com/article.cfm? colID $=8$ \&articleID $=00078 \mathrm{AD}$ 2-C873-1DF7-9733809EC588EEDF

Changnon S, Pielke RS Jr, Changnon D, Sylves RT, Pulwarty R (2000) Human factors explain the increased losses from weather and climate extremes. Bull Am Meteorol Soc 81: 437-442

Chen CC, McCarl BA (2000) The value of ENSO information 
to agriculture: consideration of event strength and trade. J Agric Resour Econ 25:368-385

Chen CC, McCarl BA, Adams RM (2001) Economic implications of potential ENSO frequency and strength shifts. Clim Change 49:147-159

Chen CC, McCarl BA, Hill HSJ (2002) The value of ENSO information under alternative ENSO phase definitions. Clim Change 54:305-325

Everingham YL, Muchow RC, Stone RC, Coomans DH (2003) Using southern oscillation index phases to forecast sugarcane yields: a case study for Northeastern Australia. Int J Climatol 23:1211-1218

Forgo F, Fulop J, Prill M (2005) Game theoretical models for climate change negotiations. Eur J Operational Res 160: 252-267

Fudenberg D, Tirole J (1991) Game theory. MIT Press, Cambridge, MA

Glantz MH (1977) The value of a long-range weather forecast for the West African Sahel. Bull Am Meteorol Soc 58: $150-158$

Hamlet AF, Huppert D, Lettenmaier DP (2002) Economic value of long-lead streamflow forecasts for Columbia River hydropower. J Water Resour Plan Manage 128: 91-101

Hansen B (1982) A survey of general equilibrium systems, reprint edition w/ corrections. Robert E. Krieger Publishing Company, Malabar, FL

Hill HSJ, Mjelde JW (2002) Challenges and opportunities provided by seasonal climate forecasts: a literature review. J Agric Appl Econ 34:603-632

Hill HSJ, Mjelde JW, Rosenthal W, Lamb PJ (1998) The potential impacts of the use of southern oscillation information on the Texas aggregate sorghum production. J Clim 12: $519-530$

Hill HSJ, Mjelde JW, Love HA, Rubas DJ, Fuller SW, Rosenthal W, Hammer G (2004) Implications of seasonal climate forecasts on world wheat trade: a stochastic, dynamic analysis. Can J Agric Econ 52:289-312

Hoyle JE, Mjelde JW, Litzenberg KK (2006) Weather to make a decision. Sci Scope 29:24-27

Jones JW, Hansen JW, Royce FS, Messina CD (2000) Potential benefits of climate forecasting to agriculture. Agric Ecosyst Environ 82:169-184

Maurer EP, Lettenmaier DP (2004) Potential effects of longlead hydrologic predictability of Missouri River main-stem reservoirs. J Clim 17:174-186

McKelvey R, Miller KA, Golubtsov P (2003) Fish-wars revisited: a stochastic incomplete-information harvesting game. In: Wesseler J, Weikard HP, Weaver RD (eds) Risk and uncertainty in environmental and natural resources economics. Edward Elgar Publishing, Northampton, MA, p 93-112

Meza FJ, Wilks DS (2004) Use of seasonal forecasts of sea surface temperature anomalies for potato fertilization

Submitted: June 16, 2005; Accepted: March 27, 2006 management: theoretical study considering EPIC model results at Valdivia, Chile. Agric Syst 82:161-180

Mjelde JW, Thompson TN, Nixon CJ (1996) Government institutional effects on the value of seasonal climate forecasts. Am J Agric Econ 78:175-188

Mjelde JW, Penson JB Jr, Nixon CJ (2000) Dynamic aspects of the impact of the use of improved climate forecasts in the corn belt region. J Appl Meteorol 39:67-79

Nelson RR, Phelps ES (1996) Investment in humans, technological diffusion, and economic growth. Am Econ Rev 56: 69-75

Rasmusen E (1992) Games and information an introduction to game theory, reprint with corrections. Blackwell Publishers, Oxford

Ritche JW, Zammit C, Beal D (2004) Can seasonal climate forecasting assist in catchment water management decision-making? A case study of the border rivers catchment in Australia. Agric Ecosyst Environ 104:553-565

Rogers EM, Stanfield JD (1968) Adoption and diffusion of new products: emerging generalizations and hypotheses. In: Bass FM, King CW, Pessemier EA (eds) Applications of the sciences in marketing. John Wiley, New York, p 227-250

Rubas D (2004) Technology adoption: Who is likely to adopt and how does the timing affect the benefits? PhD Dissertation, Texas A\&M University, College Station, TX

Rubas DJ, Mjelde JW, Love HA, Rosenthal W (2005) Who benefits from technology adoption? A case study of wheat producers adopting ENSO-based forecasts. Work Pap, Department of Agricultural Economics, Texas A\&M University, College Station, TX

Scott MJ, Vail LW, Jaksch J, Stöckle CO, Kemanian A (2004) Water exchanges: tools to beat El Niño climate variability in irrigated agriculture. J Am Water Resour Assoc 40: $15-31$

Sheriff G, Osgood D (2005) Shepherd's dilemma. Paper presented at the Am Agric Econ Annu Meet, Providence, RI. Available as Work Pap, Columbia University, New York

Stone RC, Auliciems A (1992) SOI phase relationships with rainfall in Eastern Australia. Int J Clim 12:625-636

Thalwitz WP (1990) Foreward. In: Kreimer A, Munasinghe M (eds) Managing natural disasters and the environment; selected materials from the colloquium on the environment and natural disaster management. World Bank, Washington, DC

Tomek WG, Robinson KL (2003) Agricultural product prices. 4th edn. Cornell University Press, Ithaca, New York

UN (2005) World conference on disaster reduction. Agenda item 12. Building the resilience of nations and communities to disasters: Hyogo Framework for action 2005-2015. A/conf.206/L.2/Rev.1, Kobe

Ward H (1996) Game theory and the politics of global warming: the state of play and beyond. Polit Sci 44:850-871

Proofs received from author(s): November 8, 2006 